Brazilian Journal

of Chemical

\title{
STUDY OF CONTINUOUS RHEOLOGICAL MEASUREMENTS IN DRILLING FLUIDS
}

\author{
S. da C. Magalhães Filho ${ }^{1 *}$, M. Folsta ${ }^{2}$, E. V. N. Noronha ${ }^{1}$, \\ C. M. Scheid ${ }^{1}$ and L. A. Calçada ${ }^{1}$ \\ ${ }^{1}$ Department of Chemical Engineering, Federal Rural University of Rio de Janeiro, BR 465, km 7, 23890-000 Seropédica, Brazil, \\ *E-mail: sergio1412@gmail.com; sergiomagalhaes@sergiomagalhaes.eng.br
}

${ }^{2}$ PETROBRAS S.A/CENPES, Humavenue, Square 07, Ilha do Fundão, 21494-000 Rio de Janeiro, RJ, Brazil.

(Submitted: August 4, 2015; Revised: April 14, 2016; Accepted: April 17, 2016)

\begin{abstract}
Drilling an oil well involves using drilling fluids that perform cleaning and cooling functions, but that most importantly maintain the fluids of the geological formation contained by hydraulic pressure. A fundamental role in predicting the hydraulic pressure of the well consists of monitoring the fluid's rheological behavior. This paper summarizes an ongoing effort to measure, by evaluating the performance of two online viscometers, drilling fluids' rheological behavior in real time. One online method proposes a modified Couette system. The other consists of a standard pipe viscometer with default modeling. The performances of the online devices were compared with an offline method - a Couette device commonly used in oilfields as a benchmark. For Newtonian fluids, agreement between the rheological behaviors was found for all instruments, validating the methodology proposed. For non-Newtonian fluids, there were divergences, which were investigated and their probable causes determined to be the following: homogeneity, slippage effects, and interaction in the fluid/gap interfaces. A case study demonstrated that these divergences were not significant during the prediction of hydraulic pressure, meaning that the methodology proposed has the potential to improve overall drilling performance.
\end{abstract}

Keywords: drilling fluid, online rheology, automation, continuous measurement.

\section{INTRODUCTION}

Drilling petroleum wells in ultra-deep water is an operation of great cost and risk. Due to the extreme pressure and temperature conditions, the operational window of hydraulic pressure control is too narrow for mistakes. This window represents the minimum and maximum pressures that can be applied to the system so as to avoid undesired flows towards the well, such as water or gas invasion originating from the rocks. The minimum pressure is known as porous pressure and the maximum is known as fracture pressure (Shaughnessy et al., 2007). To maintain the hydraulic pressure within the limits of the porous and fracture pressures, a common technique is the overbalanced technique. (In fact, the majority of Brazilian petroleum wells have been drilled in this manner.) In this technique, the operator pumps a drilling fluid throughout the well. To control the hydraulic pressure, it is necessary to characterize the rheological behavior of the fluid. Without such a parameter, it is impossible to predict hydraulic pressure and consequently maintain control.

In oilfields, operators carry out rheological measurements using offline viscometers that make use of manual procedures which date back more than 50 years. The evaluation of this process can be enhanced with online measurements. They can shorten distances between control centers and the field. Online measurements permit the predicting of hydraulic pressure almost instantly,

\footnotetext{
* To whom correspondence should be addressed
} 
contributing to a more precise pressure control. In addition, constant monitoring allows problems to be detected earlier, permitting the operators to mitigate costly operational problems ahead of time (Oort and Brady, 2011).

Despite such benefits, works are scarce regarding online measurements of drilling fluids during flow. Their scarcity mainly arises because such fluids usually impose several operational difficulties during measurements (Apaleke et al., 2012, Gandelman et al., 2013).

Most drilling fluids are pseudo-plastic and have thixotropic effects. They tend to be dense because of a large amount of insoluble materials in suspension, are opaque, and can be water- or oil-based. The majority of standard offline viscometers and rheometers fail to characterize such fluids due to clogging, abrasion damage, bad homogeneity, or slippage effects. Considering the vast online technological market, few devices have been designed to monitor drilling fluids (Caenn and Chillingar, 1996).

Saasen et al. (2009) built a large-scale drilling fluid flow loop to measure several drilling fluid properties, including viscosity. The authors also used a Couette viscometer. Although many properties were investigated, there were no comparisons between online data with standard bench offline ones.

Broussard et al. (2010) developed their own density and viscosity meter; both measurements were done in the same apparatus. Unlike Saasen et al. (2009), the authors compared online measurements directly with offline ones obtained in standard bench devices. Their results showed agreement, as well as disagreement, during certain periods of trial. The main reasons which caused the deviance between online and offline data were not completely pointed out, but it was suggested that the differences may lie in geometry and drifting forces that existed in the online environment. Broussard et al. (2010) also used the Couette method for measuring the rheological behavior of drilling fluids.

Rondon et al. (2012) developed a prototype to be inserted into a drilling column to measure, from pressure drop readings, the rheological behavior of the fluid in real time in downhole conditions. Their online results were compared to standard benchmark devices, but only for polymeric solutions; drilling fluids have yet to be evaluated.

Carlsen et al. (2012) installed pressure sensors across a rig site, measuring gauge pressure and differential pressure at several different points during drilling operations. From hydraulic modeling, the author predicted the apparent viscosity from those pressure readings, all measurements were done at the surface. The online measurements were compared to standard bench devices and presented similar behavior found in Broussard's work.

Vajargah and Oort (2015) proposed a method to determine rheology in real time from downhole measurements of pressure drop and temperature, considering the well as an annulus pipe viscometer. Their results were compared to offline data taken from an offline high-pressure high-temperature rheometer. Their paper does not extensively compare online and offline data.

The present work develops a Couette viscometer to continuously measure rheology on the surface, with no flow-rate limitation and up to pressures of $200 \mathrm{psi}$ and $145^{\circ} \mathrm{C}$. It also constructs a pipe viscometer for online comparison purposes. Online and offline data are also compared. In a case study, the pressure drop is calculated in real time using online data and compared with the data calculated from the offline device.

This paper stands out in demonstrating a newly developed device, optimized for drilling fluids, which needs no qualified personnel to operate, due to its high level of automation. The results demonstrate that the methodology proposed is of potential utility for any industry that may require hydraulic pressure control, rheological control or monitoring.

\section{MATHEMATICAL MODELS REVIEW}

\section{Online/offline concentric cylinder viscometers (Couette viscometers)}

A Couette viscometer calculates shear stress by measuring the drag force on the inner cylinder, transferred by the fluid contained in the gap. This force originates in the outer cylinder, which is rotated by a motor. The gap is the annulus space formed between the two concentric cylinders (inner and outer).

The shear stress for online or offline Couette viscometers, for Newtonian and non-Newtonian fluids, is calculated by (Barnes, 2000):

$$
\tau=\left(\frac{k}{2 \pi r_{1}^{2} H}\right) \theta
$$

where $k$ is the elastic constant of the spring or torque sensor, $r_{1}$ is the inner cylinder radius, $H$ is the height of the inner cylinder and $\theta$ is the deflected angle of the torsion spring or sensor.

For Ostwald-de-Wale fluids, the shear rate for online/ offline Couette viscometers (Barnes, 2000) is determined as follows:

$$
\dot{\gamma}=\Psi_{(n)}\left(\frac{2 r_{2}^{2}}{r_{2}^{2}-r_{1}^{2}}\right) \omega
$$




$$
\begin{gathered}
\Psi_{(n)}=\left(\frac{\beta^{\frac{2}{n}}}{n \cdot \beta^{2}}\right)\left(\frac{\beta^{2}-1}{\beta^{\frac{2}{n}}-1}\right) \\
\beta=r_{2} / r_{1} .
\end{gathered}
$$

where $\Psi_{(\mathrm{n})}$ is a dimensionless factor, $r_{2}$ is the radius of the outer cylinder, $r_{1}$ is the radius of the inner cylinder, $\omega$ is the angular velocity of the rotating cylinder (outer one if the viscometer is a Couette system) and $\mathrm{n}$ is the behavior index of the fluid.

It can be seen in Eq. (2) that the shear rate for nonNewtonian fluids depends on the behavior index and ratio of the radii (the ratio is the gap of each instrument). Barnes (2000) showed that the behavior index can be calculated using the approximation:

$$
n=n=\frac{d \ln (\tau)}{d \ln (\omega)}
$$

where data of $\tau$ and $\omega$ are determined experimentally.

\section{Online capillary or pipe viscometers}

For the laminar flow (Bird et al., 2001)of a fluid inside a straight circularpipe:

$$
\frac{-\partial P}{\partial z}=\frac{1}{r} \frac{\partial}{\partial r}\left(r \tau_{r z}(r)\right)
$$

Where $P$ is the gauge pressure at position $z$ (axial) and $r$ (radial). From Equation (7), the shear stress is obtained by:

$$
\tau_{r z}(R)=\frac{\Delta P . R}{2 . L}
$$

and shear rate,

$$
\dot{\gamma}_{R}=\frac{4 Q}{\pi R^{3}}\left[\frac{3+(1 / n)}{4}\right]
$$

where $\tau_{r z}(R)$ is the shear stress at the pipe wall, $\Delta P$ is the pressure drop, $R$ is the pipe internal radius and $L$ is length, $\dot{\gamma}_{R}$ is the shear rate at the pipe wall, and $Q$ is the volumetric flow rate.

\section{MATERIALS AND METHODS}

\section{Flow loop}

The flow loop was built not only to develop the online equipment, but also to make and produce the necessary drilling fluids, whether oil-based or water-based. A brief description of the apparatus is found in Fig. 1:

- A500-liter tank coupled with a high power and speed mixer;

- A3-hppositive displacement pump that drives the fluid to the pipe lines;

- A centrifugal pump in parallel to flush the system during or after experiments;

- A heat exchanger to heat up or cool down the fluid;

- An online instrumentation to measure the desired fluid properties and control operational conditions such as flow rate, discharge pressure, pressure drop and temperature;

- To communicate with the equipment, hardware was used that was provided by National Instruments, along with the software LabVIEW ${ }$, with which the humanmachine interface was constructed.

The online viscometers TT-100 and pipe can be identified in Fig. 1 by numbers 10 and 8, respectively. TT100 performs both shear rate and shear stress measurements. The pipe viscometer generates shear stress by the pressure drop measured in the instrument numbered 8 , and the shear rate is calculated by the determination of the volumetric flow rate, which is provided by the instrument numbered 7 , a Coriolis mass flow meter. 

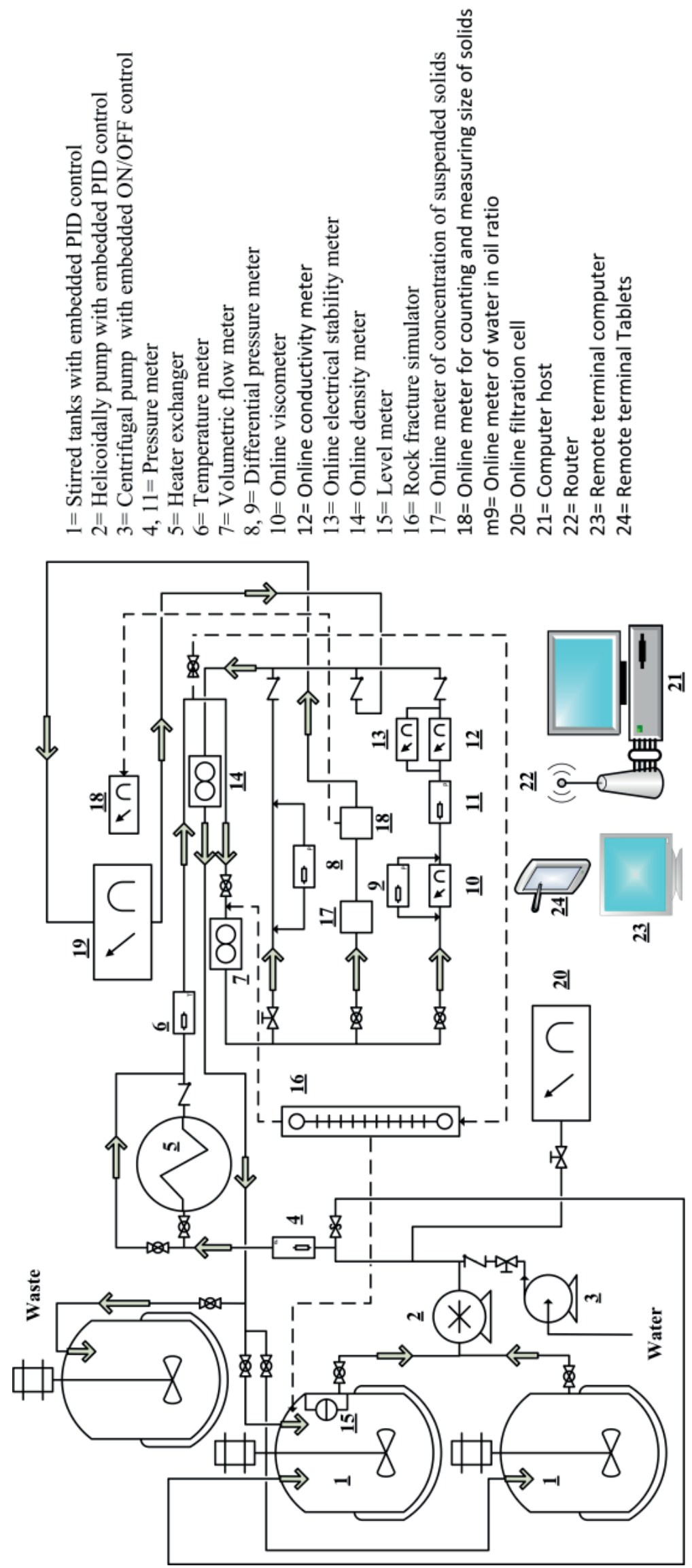

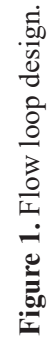




\section{Viscometers}

\section{Couette viscometer, online and offline}

The Couette measurement system is present in TT100 , an online viscometer, and in FANN 35A, an offline viscometer. Figure 2 illustrates the mechanical parts of TT100 (Brookfield manual, 1993).

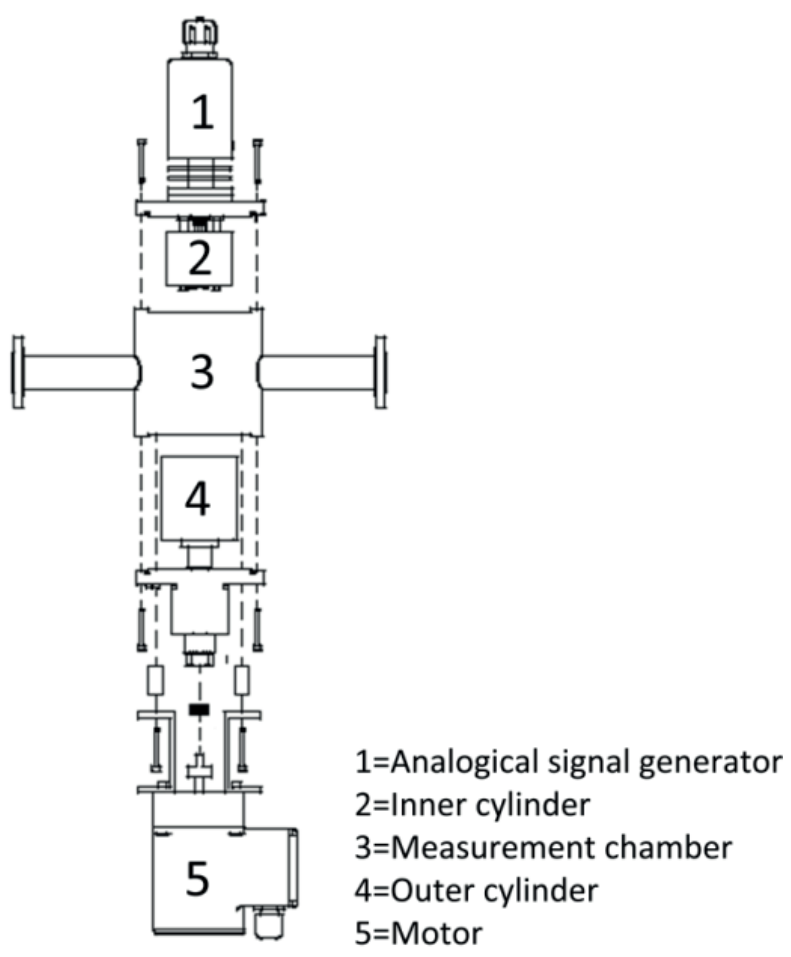

Figure 2. Viscometer BROOKFIELD, model TT-100, original motor.
It can be observed in Fig. 2 that the gap for TT-100 is formed when the number 2 and 4 pieces are assembled. The original TT-100 comes with a DC motor with seven fixed velocities, manually controlled.

The objective was not only to determine rheological behavior, but to control the equipment remotely. So the original instrument was modified by replacing the DC motor with an $\mathrm{AC}$ brushless servomotor. These types of motors are controlled with a special vector inverter device, which allows full access to several motor parameters, such as speed, torque, and spin control. The motor replacement also permits capturing the velocity of the motor (RPM) in real time.

As a result of the online configuration, the operating principles of TT-100 are the same for any default Couette viscometer - with the exception of the fluid renewal inside the measurement chamber. If the fluid changes its rheological characteristics, TT-100 will report so as soon as this fluid arrives in the gap.

The offline instrument evaluates the shear stresses at six different shear rates. The velocities of the outer cylinder can be selected by manipulating simultaneously the speed selector along with the gear shift. The velocities are 3, 6, 100, 200, 300, and 600 RPM. The shear stresses, in each motor velocity, are calculated from the values of deflected angle, which can be read in the analogical display on top of the instrument.

Pipe viscometer

From experimental data of volumetric flow rate and pressure drop, it was possible to estimate the shear rate and shear stress, respectively, using the mathematical models illustrated above. Figure 3 shows the constructed viscometer in greater detail.

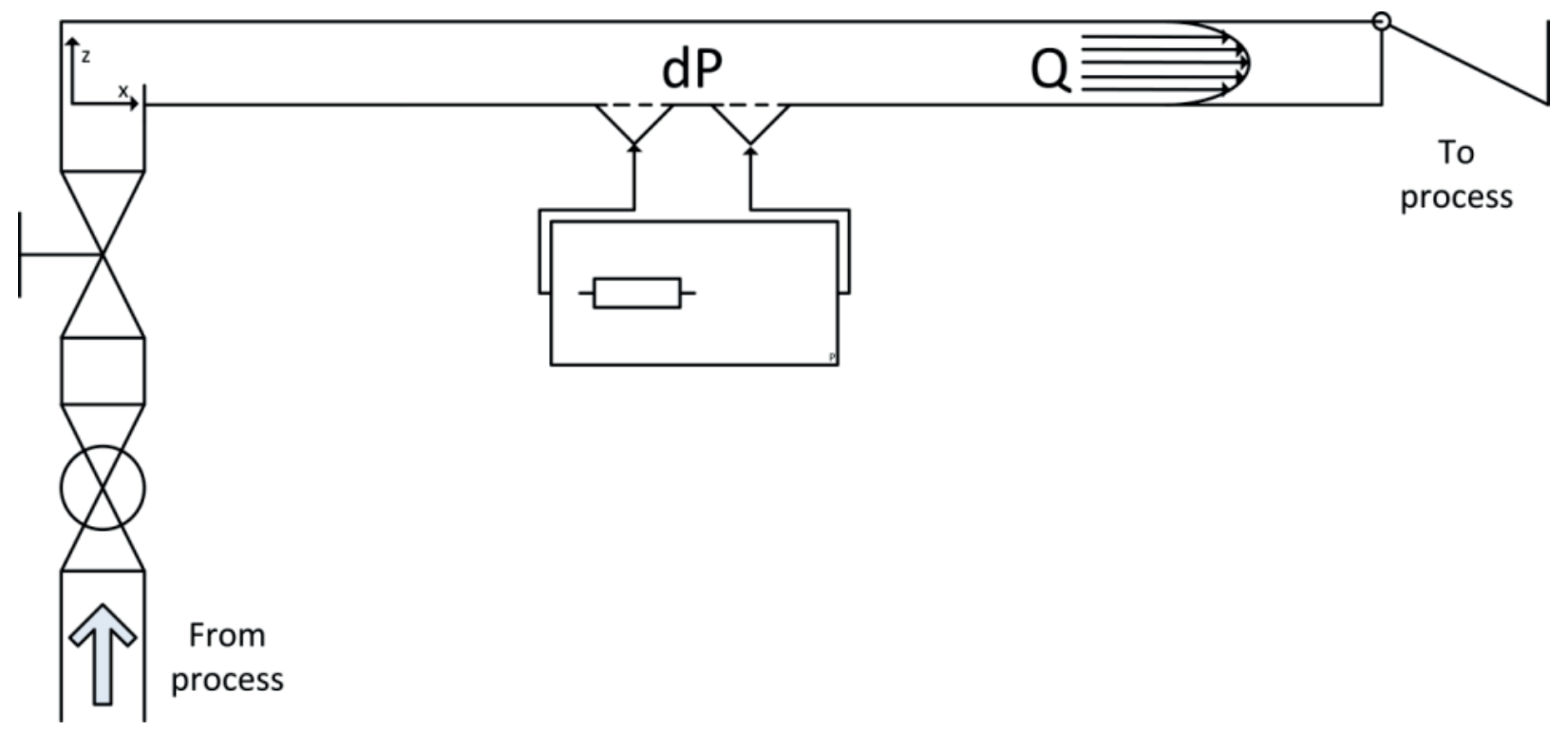

Figure 3. Operational principles of pipe viscometer. 


\section{Experimental design}

\section{Fluids and experimental procedure}

To investigate rheology online, the study used three different fluids - one exhibiting Newtonian behavior and two exhibiting Non-Newtonian behavior. The Newtonian fluid was used to calibrate and validate the installed equipment. Because the fluid had fewer rheological complexities, it was expected that all viscometers would provide similar data. After validation, a polymeric solution was used to evaluate the performance of each viscometer against non-Newtonian fluid behavior. Finally, and of most interest, all instruments were tested with a water-based drilling fluid, typically used in drilling processes; the fluid has solids in suspension, in a medium concentration range (30 to $60 \%$ in mass). Table 1 presents these fluids' properties, such as composition and density.

Table 1. Evaluated fluids.

\begin{tabular}{cccc}
\hline Type & Viscosity & Composition & Density $(\mathrm{g} / \mathrm{cm} 3,250 \mathrm{C})$ \\
\hline Newtonian & Constant & Glycerin $75 \%$ & $\sim 1,0$ \\
Non-Newtonian & Low range & CMC* solution $0,25 \%$ w/w & $\sim 1,0$ \\
Non-Newtonian & High range & CMC* solution $1 \%$ w/w & $\sim 1,0$ \\
Non-Newtonian & High range & Water based mud & $\sim 1,5$ \\
\hline
\end{tabular}

*CMC = Carboxyl Methyl Cellulose

The basic composition of the water-based mud was water, bentonite, barite, calcium carbonate, sodium hydroxide, xanthan gum, glutaraldehyde, and a rheological modifier.

The experimental procedure consisted of acquiring, at the same time, the rheological profile of the chosen fluid at the same temperature in all three instruments-TT-100, FANN 35A, and pipe viscometer.

\section{Mathematical procedure}

According to Billon (1996), many viscometers are sold to be used with Non-Newtonian fluids containing mathematical procedures only valid for Newtonian fluids to calculate apparent viscosity, shear rate and shear stress. The literature shows that the velocity gradients for nonNewtonian fluids formed in a gap or during tube flow are not as parabolic as for Newtonian fluids. The smaller the value of $\mathrm{n}$, the more non-linear is the profile formed by the gradient velocity. Hence, the shear rate for non-Newtonian fluids, regardless of the geometry of the flow, depends directly on the behavior index and gap size. Ignoring these terms can lead to a miscalculation. As a result, an algorithm was built in a LabVIEW ${ }^{\circledR}$ environment to solve Eq. (2). The algorithm applies a linear fit to the logarithm of the income data of shear stress and motor speed. This algorithm can determine the slope of the line formed between those logarithms, which is n' (Eq. (5)). This calculation allows the prompt determination of the dimensionless coefficient (Eq. (3)) necessary to calculate the shear rate of Ostwaldde-Waele fluids.

The linear fit is based on the iterative model (LabVIEW ${ }^{\circledR}$ instruction manual) represented by:

$$
\text { residual }=\frac{1}{N} \sum_{i=0}^{N-1} w_{i}\left(\hat{y}_{i}-y_{i}\right)^{2}
$$

where $\mathrm{N}$ is the number of data received, $w_{i}$ is the ith element of weight, $\hat{y}_{i}$ is the ith element of best linear fit and $y_{i}$ is the ith element of incoming data (dependent variable). This study considered the weight equal to 1 and the tolerance equal to 0.0001 .

For the offline viscometer, the linear fit was done using a native algorithm from the software ORIGIN ${ }^{\circledR}$, which is also based on the Least Square Method (LSM).

\section{RESULTS AND DISCUSSION}

\section{Online rheology results}

All evaluations were done at two different temperatures and in triplicate. The figures will only show the typical average result at lower temperature. Complete data can be observed in the tables.

Figure 4 presents the rheological behavior and its statistics for glycerin. The statistical information can be seen under the rheological profiles, respectively, according to the horizontal aligned axis.

The behavior of the plotted shear stress versus shear rate was, as expected, a straight line, characteristic of a Newtonian behavior. TT-100 presented some divergence above $750 \mathrm{~s}^{-1}$. Besides that, all equipment presented similar data.

The measurement range of the pipe viscometer was limited by pump rotation and flow regime. Its inferior limit 


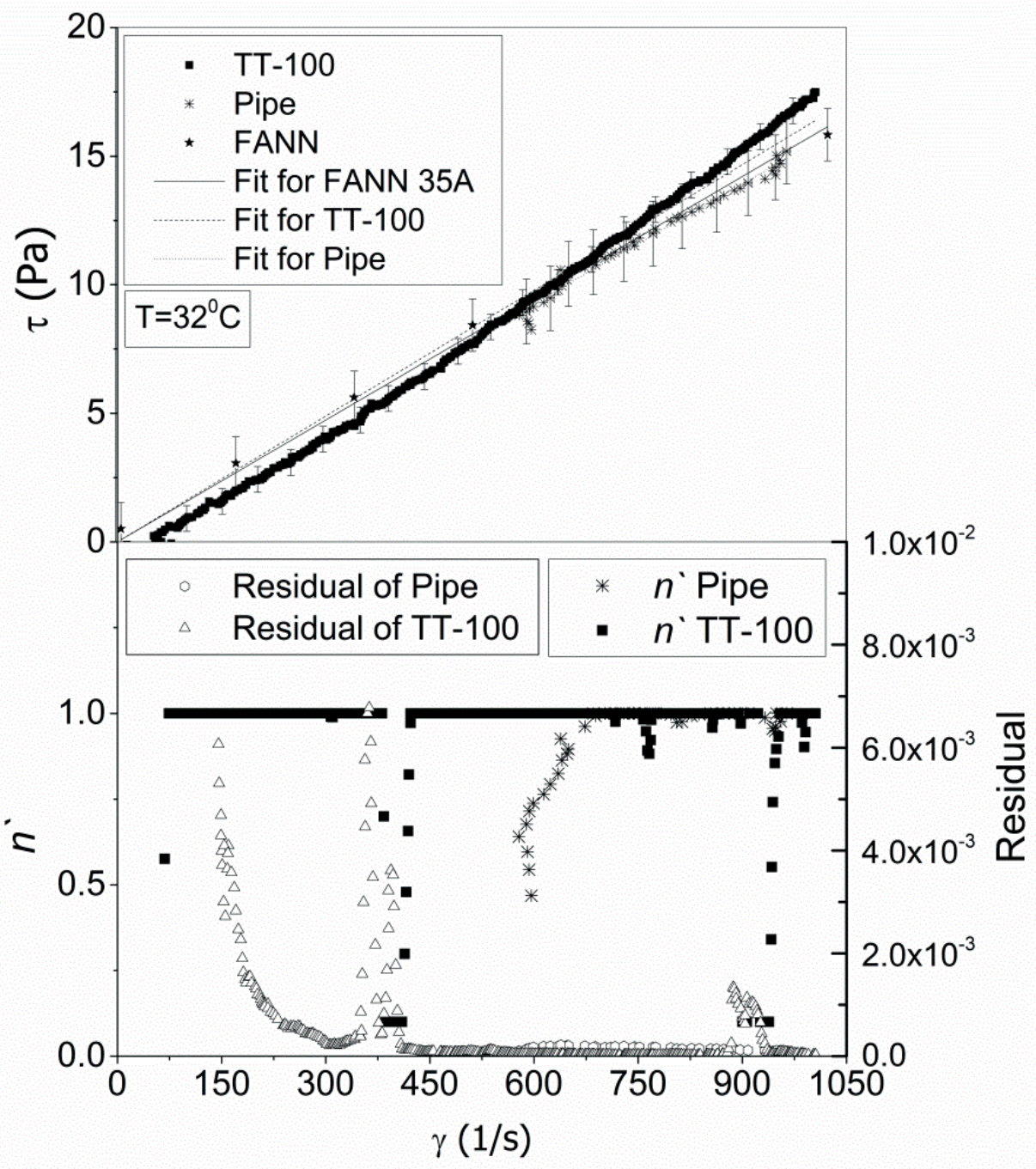

Figure 4. Shear stress versus shear rate for glycerin and its statistical results.

was the minimum rotating speed of the pump, and the superior limit was the maximum flow rate to maintain the laminar regime.

One may also note the error bars, which represent the error propagation caused by sensor imprecision. Table 2 shows that all imprecisions accounted for this error propagation. The mathematical method used was the derivative one (Meyer, 1975).

In Fig. 4, it can be noted that the residual of TT100was larger than that of the pipe viscometer at the beginning of operation, despite being smaller until the end of the experiment. Thereby it is possible to infer that the incoming data $(\ln (\tau)$ and $\ln (\omega))$ of TT-100 was more accurate than that of the pipe viscometer. This is acceptable because the pump vector inverter is not as precise as the servomotor vector inverters. Despite the larger residual at the beginning of the operation, TT-100 converged its slope faster than did the pipe viscometer.

To obtain the parameter $\mu$ of the Newtonian model, another linear fit was applied, but now using data of shear rate and shear stress. This fit was done using the software ORIGIN®, which received the exported data from LabVIEW®.

The obtained results of viscosity $(\mu)$ and the performance of the fit $\left(\mathrm{R}^{2}\right.$ - correlation coefficient) are presented in Table 3.

The results presented for $n$, in Table 3 , permit the conclusion that the hypothesis of $n=n$ ' was acceptable.

To evaluate data for non-Newtonian fluid, a dilute solution of CMC was fabricated, approximately $0.25 \%$ in mass. Shown in Fig.5 is the data obtained for this fluid.

It may be observed in Fig. 5that the behavior of the 
Table 2. Imprecisions considered for error propagation.

\begin{tabular}{|c|c|c|c|}
\hline Instrument & Imprecise measure & dimension & range \\
\hline TT-100 & $\begin{array}{l}\text { Deflected angle } \\
\text { Motor velocity }\end{array}$ & $\begin{array}{c}\text { degree } \\
\text { RPM }\end{array}$ & $\begin{array}{l} \pm 1 \% \\
\pm 1\end{array}$ \\
\hline FANN 35A & Deflected angle & degree & \pm 1 \\
\hline pipe & $\begin{array}{l}\text { Pressure } \\
\text { Flow rate }\end{array}$ & $\begin{array}{c}\mathrm{Pa} \\
\mathrm{m} 3 / \mathrm{s}\end{array}$ & $\begin{array}{l} \pm 1 \% \\
\pm 1 \%\end{array}$ \\
\hline
\end{tabular}

Table 3. Estimated $\mu$ for glycerin $50 \%$ and statistical results.

\begin{tabular}{ccccc}
\hline Instrument & $\mu(\mathrm{cP})$ & $\mathrm{R}^{2}$ & $n$ & $\mathrm{~T}\left({ }^{\circ} \mathrm{C}\right)$ \\
\hline TT-100 & $16.3 \pm 5.5 \times 10-5$ & 0.98 & 1 & 32 \\
FANN 35A & $15.8 \pm 3.2 \times 10-4$ & 0.99 & 1 & 32 \\
pipe & $15.5 \pm 5.4 \times 10-5$ & 0.98 & 1 & 32 \\
TT-100 & $9.1 \pm 5.2 \times 10-5$ & 0.95 & 1 & 50 \\
FANN 35A & $8.6 \pm 2.3 \times 10-4$ & 0.99 & 1 & 50 \\
pipe & $8.2 \pm 6.2 \times 10-5$ & 0.94 & 1 & 50 \\
\hline
\end{tabular}

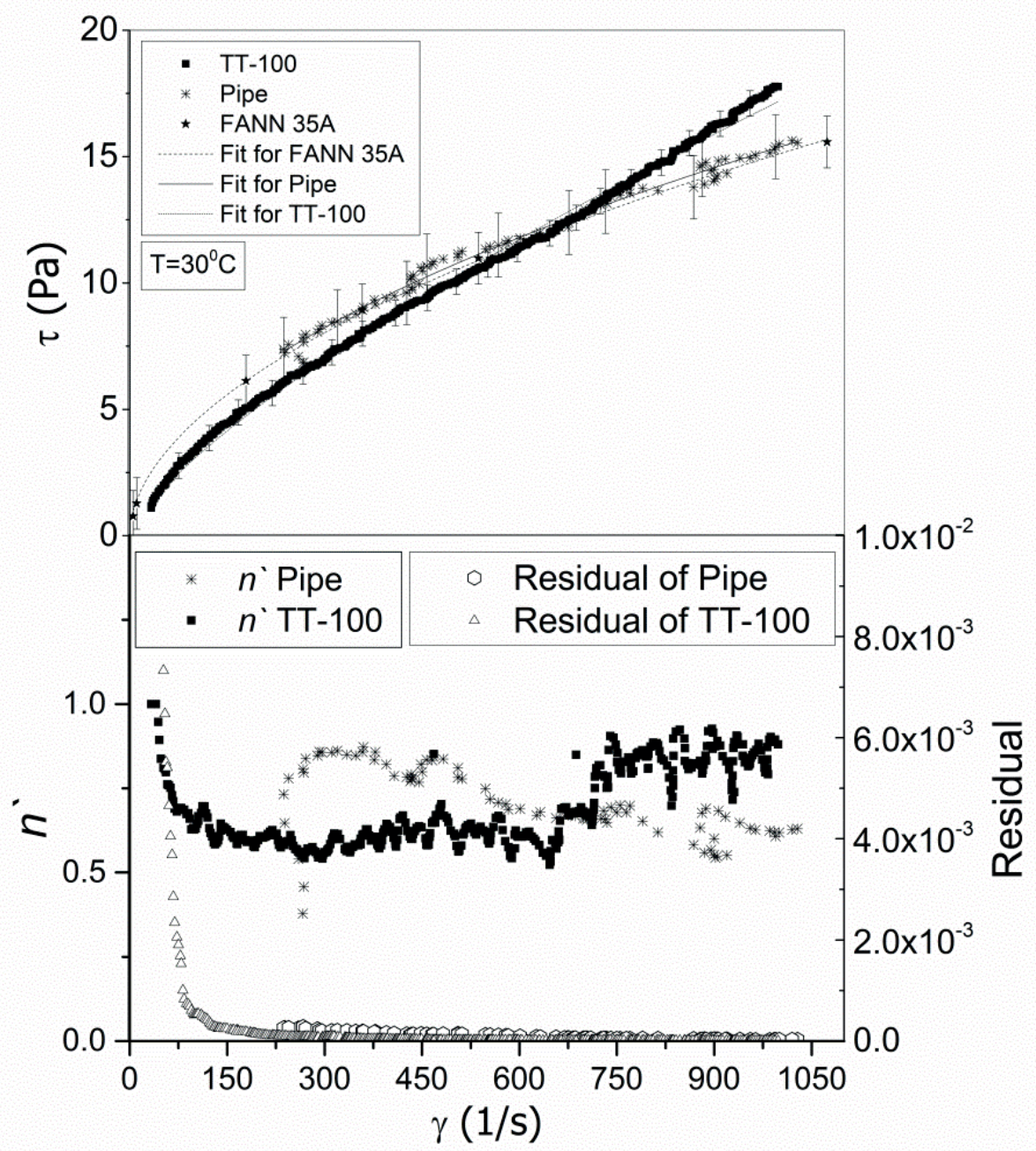

Figure 5. Shear stress versus shear rate for dilute $0.25 \% \mathrm{CMC}$ and its statistical results. 
curve is characteristic of an Ostwald-de-Waele fluid, more precisely a pseudo-plastic. To represent the curve a power law model was used. One may note once more the deviance for TT-100 rheological behavior after $750 \mathrm{~s}-1$. Besides that, all equipment generated similar data.

The linear fit results presented are accurate. It may also be noticed that the slope is more dynamical than it was for Newtonian fluids. Usually rheological behavior measured online is subject to effects absent from batch offline systems because, in the process, a perfect steady state would never be achieved (Himmelblau and Rigs, 2003). Evaluating the results in Fig. 5, it can be understood that these effects are more pronounced with non-Newtonian fluids than with Newtonian ones. The objective of having a dynamical n' is to see how it impacts the final rheological profiles.

The $\mathrm{n}$ ` for TT-100 was similar to that of FANN 35A, until it started to deviate to approximately 0.87 . The slope of the pipe viscometer did not maintain a constant value and diverged from TT-100. Therefore, two Couette viscometers were observed to generate similar slopes and a pipe viscometer to diverge from them.

Table 4 shows the results for the non-linear fit of shear rate and shear stress, using the power law model to represent the rheological profiles. There are present in the table the parameters $\mathrm{K}$ and $\mathrm{n}$, which belong to the power law model, as well as n'avg and $\mathrm{R}^{2}$. The parameter n'avg is the average value of n' obtained during an entire online rheological test. This average online parameter is directly compared to the offline n'.

It can be seen in Table 4 that the values of the parameters $\mathrm{K}$ and n, for TT-100 viscometer, diverged from other instruments, probably because of its divergence at high shear rates (Fig. 5).

An increase of temperature decreases the values of the parameter $\mathrm{K}$, which is expected as $\mathrm{K}$ is the number related to the viscous aspect of the fluid. In addition, the behavior index of FANN 35A and of the pipe viscometer remain similar, but rises significantly for TT-100. This increase in the TT-100 index happened because the slope did not diverge as it had in the previous experiment with low temperature. Any changes in the rheological profile affect directly the parameters estimated.

The divergences at a certain point for TT-100must be related to shear stress, which depends directly on the torque sensor engineering. This behavior was investigated to see if it was present during measurements in fluids with higher viscosities. The results of $1 \% \mathrm{CMC}$ are presented in Fig. 6 and Table 5.

Figure 6 shows no more deviances at high shear rates for the TT-100 viscometer. It was thus concluded that the torque sensor of the studied instrument was more adequate and accurate for high-range viscosity measurements. This brings up one disadvantage of Couette systems; one should make preliminary tests to choose a torsion element adequate to the viscosity range of interest (Brookfield instruction manual, 1993 and Fann instruction manual, revision J 208878).

The power law parameters for this system can be seen in Table 5.

The parameter $\mathrm{n}$ ' for the pipe viscometer and FANN $35 \mathrm{~A}$ diverged from $\mathrm{n}$, but for TT-100 was accurate. When comparing data in Tables 5 and 4 (the same temperature, but Table 4 was $0.25 \% \mathrm{CMC}$ ), it should also be noted that, as expected, an increase in the polymer concentration makes $\mathrm{K}$ rise (becoming more viscous) and $\mathrm{n}$ drop (becoming more non-Newtonian).

Making the fluid more non-Newtonian, with lower values of $n$, causes a pronouncement of some effects, such as gap size, border effects, and pressure drop effects. This is experimental evidence which explains why $\mathrm{n}$ and $\mathrm{n}^{\mathrm{\prime}}$ diverged for FANN 35A and pipe viscometer. For FANN $35 \mathrm{~A}$, the gap is wider than the gap of TT-100; the wider the gap, the more pronounced is the associated error. For the pipe viscometer, the more non-Newtonian the fluid, the more difficult it is to achieve the steady state of the flowing fluid, which makes it more difficult to measure volumetric flow rate.

An increase in temperature caused, as expected, a decrease in the parameter $\mathrm{K}$. Also as expected, the parameter $\mathrm{n}$ does not vary significantly. It was noted that, for this high-range viscosity system, TT-100 was the instrument that provided the closest values of $n$ ' and $n$.

Once the effects of viscosity range and temperature on the instruments were investigated, the next step was to evaluate the effects of suspended solids in viscosity measurements during flow. Fig. 7 presents the rheological behavior ofa water-based drilling fluid with a density of $1.5 \mathrm{~g} / \mathrm{cm}^{3}$.

Table 4. Estimated $\mathrm{K}$ and $\mathrm{n}$ for dilute $0.25 \% \mathrm{CMC}$ and statistics results.

\begin{tabular}{ccccc}
\hline Instrument & $\mathrm{K}$ & $n_{\text {avg }}^{\prime}$ & $\mathrm{R}^{2}$ & 0.99 \\
\hline TT-100 & $0.10 \pm 1.90 \times 10-3$ & $0.75 \pm 2.99 \times 10-3$ & 0.69 & 0.99 \\
FANN 35A & $0.40 \pm 2.70 \times 10-2$ & $0.52 \pm 1.02 \times 10-2$ & 0.56 & 0.99 \\
pipe & $0.43 \pm 1.80 \times 10-2$ & $0.52 \pm 6.32 \times 10-3$ & 0.58 & 0.99 \\
TT-100 & $0.03 \pm 3.35 \times 10-4$ & $0.88 \pm 1.62 \times 10-3$ & 0.78 & 0.99 \\
FANN 35A & $0.24 \pm 1.80 \times 10-2$ & $0.56 \pm 1.15 \times 10-2$ & 50 & 0.58 \\
pipe & $0.16 \pm 1.13 \times 10-2$ & $0.60 \pm 1.03 \times 10-2$ & 50 & 50 \\
\hline
\end{tabular}




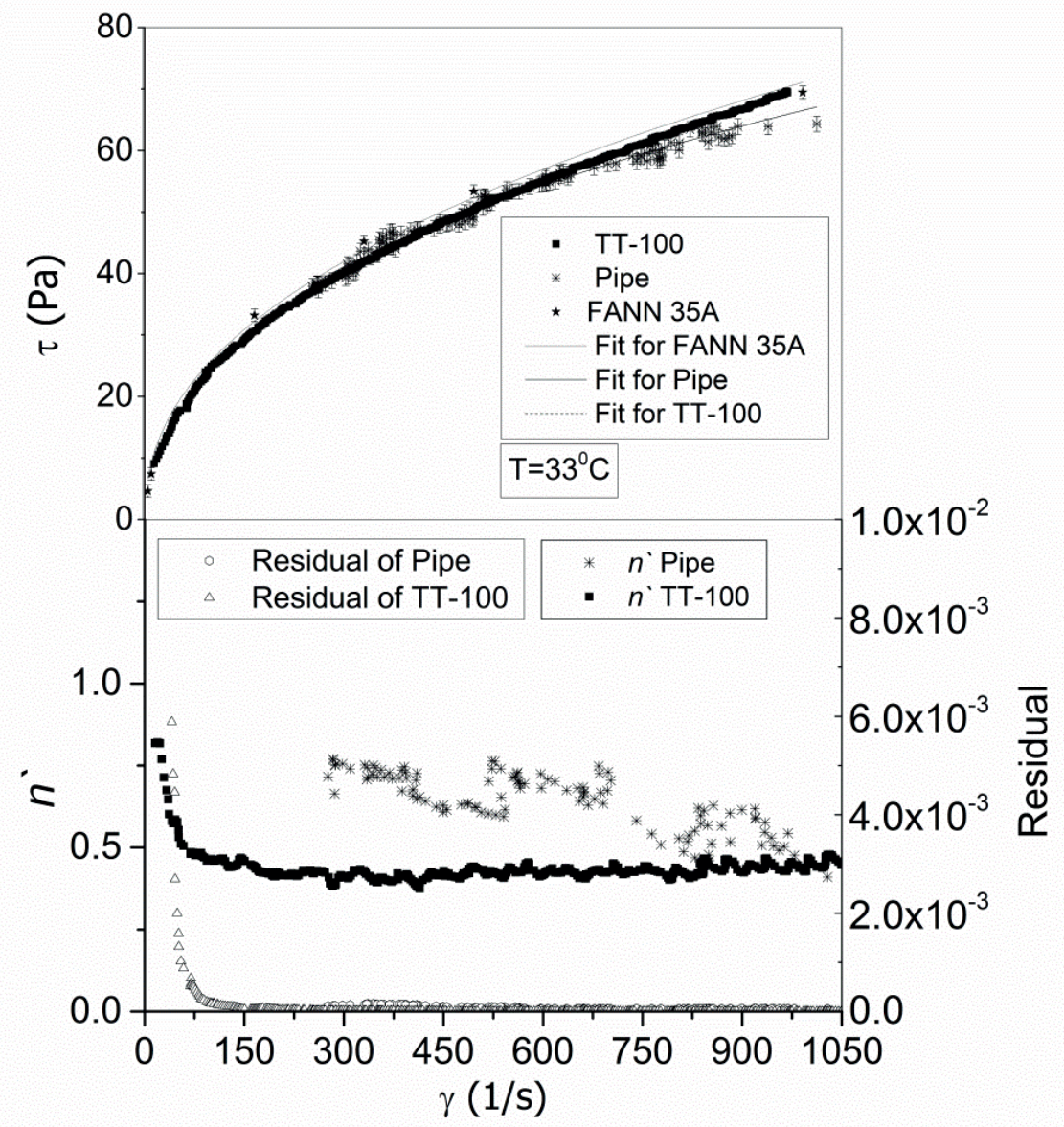

Fig. 6. Shear stress versus shear rate for $1 \% \mathrm{CMC}$ and its statistical results.

Table 5. Estimated $\mathrm{K}$ and $\mathrm{n}$ for $1 \% \mathrm{CMC}$ and statistical results.

\begin{tabular}{cccccc}
\hline Instrument & $\mathrm{K}$ & $n$ & $n_{\text {avg }}^{\prime}$ & $\mathrm{R}^{2}$ & $\mathrm{~T}\left({ }^{\circ} \mathrm{C}\right)$ \\
\hline TT-100 & $2.72 \pm 9.97 \times 10-3$ & $0.46 \pm 5.63 \times 10-4$ & 0.44 & 0.99 & 33 \\
FANN 35A & $3.24 \pm 0.52$ & $0.44 \pm 2.46 \times 10-2$ & 0.51 & 0.99 & 33 \\
pipe & $3.96 \pm 0.13$ & $0.40 \pm 4.96 \times 10-3$ & 0.58 & 0.98 & 33 \\
TT-100 & $1.19 \pm 6.85 \times 10-3$ & $0.55 \pm 8.76 \times 10-4$ & 0.53 & 0.99 & 50 \\
FANN 35A & $1.66 \pm 0.30$ & $0.50 \pm 2.76 \times 10-2$ & 0.62 & 0.99 & 50 \\
pipe & $2.08 \pm 0.14$ & $0.46 \pm 1.00 \times 10-2$ & 0.54 & 0.96 & 50 \\
\hline
\end{tabular}

After $750 \mathrm{~s}-1$, the curve of TT-100 started to diverge, as was observed previously with low-viscosity range fluids. This was unexpected because the water-based mud is a high-range viscosity fluid. Although the divergence pattern is similar to the ones that occurred in previous experiments, the root of this divergence is distinct. The literature shows that the accuracy of Couette viscometers can be susceptible to fluids with suspended solids - the more homogeneous the fluid the more accurate the measurement.

It is also known that the slippage effect can impact viscometer readings when solids are suspended. The slippage effect reduces measurement precision because the velocity of the wall (spinning outer cylinder) and the velocity of the fluid at the wall are not entirely equal anymore. In summary, it was concluded that, when evaluating fluids with suspended solids, there are at least two concomitant different effects on Couette instruments: homogeneity and slippage.

For TT-100, the sample tended to be more homogeneous than FANN 35A due to the flowing of the drilling fluid inside the measuring chamber. This flow rate, on the other hand, caused the slippage effect to be more pronounced. The $\beta$ ratio (Eq. (4)) for TT-100 is 1.04 and for FANN 1.06. The narrower the gap, the more present the slippage effect, which decreases shear stress, consequently decreasing apparent viscosity. This may explain why FANN 35A 


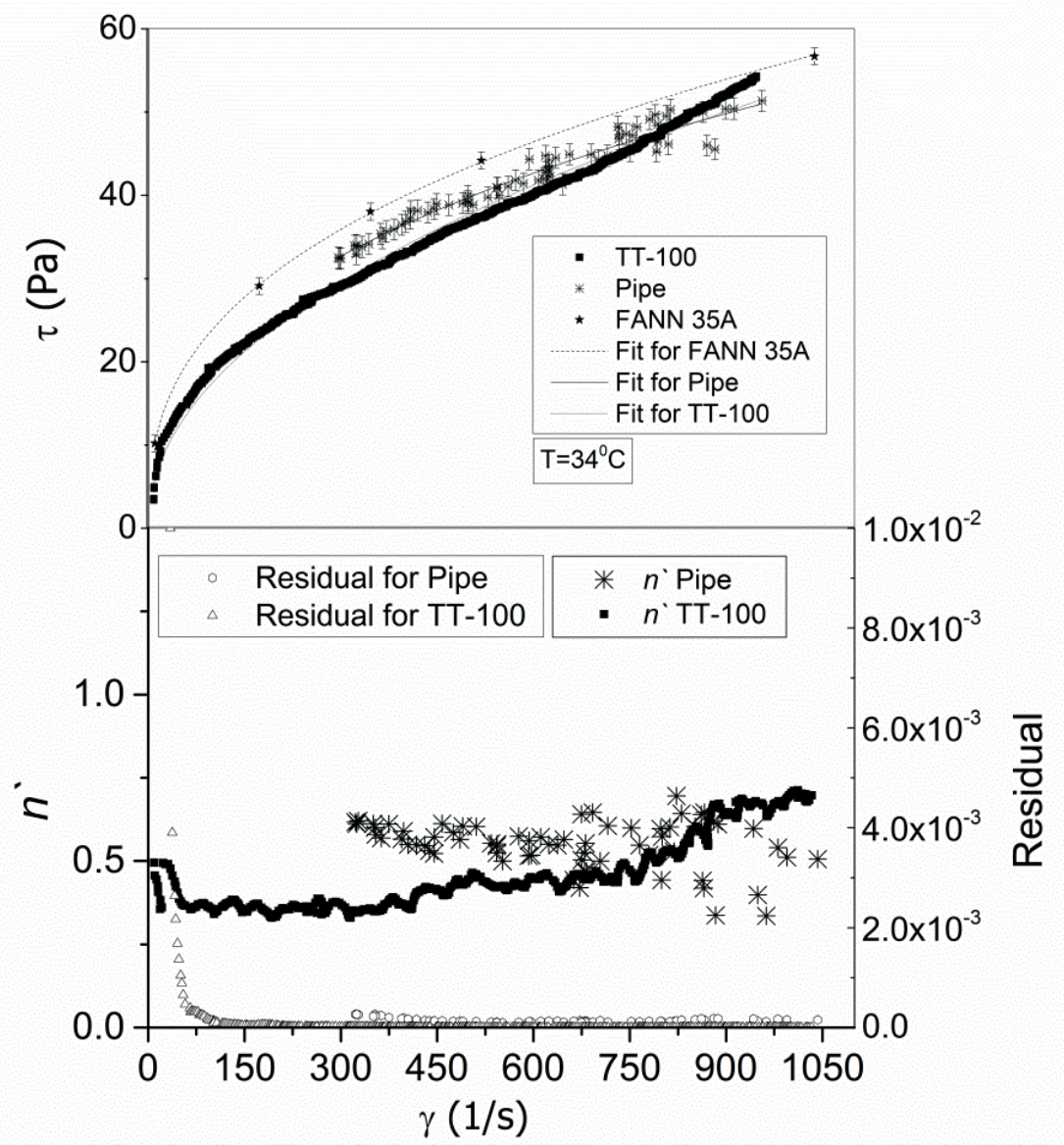

Figure 7. Shear stress versus shear rate for a water based drilling fluid and its statistical results.

presented the highest values of shear stress and TT-100 the lowest (note that this impacts directly the value of the $\mathrm{K}$ parameter). In addition, the slippage effect was more pronounced at a lower shear rate, which explains why TT100 tends, at high shear rates, to converge its rheological behavior to FANN 35A.

The rheological parameters presented in Table 6 demonstrate that the slope for TT-100 was not steady at a common average point; this may be attributable to the slippage effect.

Table 6. Estimated $\mathrm{K}$ and $\mathrm{n}$ for water-based drilling fluid and statistical results.

\begin{tabular}{cccccc}
\hline Instrument & $\mathrm{K}$ & $n$ & $n_{\text {avg }}^{\prime}$ & $\mathrm{R}^{2}$ & $\mathrm{~T}\left({ }^{\circ} \mathrm{C}\right)$ \\
\hline TT-100 & $1.85 \pm 3.51 \times 10-2$ & $0.48 \pm 2.90 \times 10-3$ & 0.46 & 0.99 & 34 \\
FANN 35A & $4.20 \pm 8.91 \times 10-2$ & $0.37 \pm 3.28 \times 10-3$ & 0.38 & 0.99 & 34 \\
pipe & $3.55 \pm 0.26$ & $0.38 \pm 1.11 \times 10-2$ & 0.51 & 0.95 & 34 \\
TT-100 & $1.34 \pm 2.88 \times 10-2$ & $0.50 \pm 3.29 \times 10-3$ & 0.48 & 0.99 & 50 \\
FANN 35A & $3.15 \pm 0.18$ & $0.39 \pm 9.07 \times 10-3$ & 0.40 & 0.99 & 50 \\
pipe & $2.60 \pm 0.26$ & $0.40 \pm 1.55 \times 10-2$ & 0.52 & 0.90 & 50 \\
\hline
\end{tabular}

The best assumption for $\mathrm{n}^{`}=\mathrm{n}$ was found using TT-100 and FANN 35A viscometers. The online linear fit for TT100 at $50^{\circ} \mathrm{C}$ presented similar behavior compared to the previous one done at lower temperature.

\section{Statistical analysis of the obtained results}

The null hypothesis test is a statistical test which allows inferences over a determined data. Considering this study, 
the null hypothesis is: changing devices does not influence the rheological parameters. To test this hypothesis, the STATISTICA software was used as computational tool. The mathematical approach used was the "Kruskal-Wallis ANOVA by Ranks". Such method does not rely on data distribution parameters (normal distribution for instance), therefore it is adequate for unknown small samples, such as presented here. The results obtained after performing the statistical test can be observed in Table 7.

Table 7. Results obtained from Kruskal-Wallis statistical test.

\begin{tabular}{|c|c|c|c|c|c|}
\hline \multirow{3}{*}{$\begin{array}{l}\text { Variable } \\
\text { Device }\end{array}$} & \multirow{3}{*}{$\begin{array}{l}\text { Coded variable } \\
\text { TT100 / FANN }\end{array}$} & \multicolumn{2}{|c|}{ Significance ( $p$-level) } & \multirow{2}{*}{\multicolumn{2}{|c|}{ Result over null hypothesis }} \\
\hline & & \multirow{2}{*}{$\begin{array}{c}\frac{K}{0.6907} \\
\end{array}$} & \multirow{2}{*}{$\begin{array}{c}n \\
0.5020\end{array}$} & & \\
\hline & & & & Accept & Accept \\
\hline Fluid & $\mathrm{G} / \mathrm{C} 1 / \mathrm{C} 2 / \mathrm{WBM}^{*}$ & 0.002 & 0.002 & Reject & Reject \\
\hline
\end{tabular}

* G - Glycerin, $\mathrm{C} 1-\mathrm{CMC}$ at $0.25 \%, \mathrm{C} 2-\mathrm{CMC}$ at $1 \%, \mathrm{WBM}-$ Water Based Mud

A 95\% confidence interval was chosen; p-level limit was automatically created at 0.05 . In Table 7 , it can be seen that this parameter was 0.002 when computing the influence of the fluid over the parameters $\mathrm{K}$ and $\mathrm{n}$. This means a probability of $99.998 \%$ that the null hypothesis is wrong, or a probability of $0.002 \%$ that the null hypothesis is right. Therefore, every p-level below 0.05 should reject the null hypothesis, as the opposite is true. In an overall analysis, considering still Table 7, the nature of the fluid presented statistical influence over the rheological parameters. On the other hand, changing devices did not. In conclusion, it can be inferred that the divergences found in the rheological parameters during the usage of different devices are not statistically relevant.

\section{Investigation of the measured rheology on friction loss determination.}

One of the major tasks during the drilling of petroleum wells is to determine the friction loss for pressure control. The rheological parameters influence this calculation directly. Thus to evaluate the impact of the different rheological behaviors obtained on the calculation of friction loss, a case study was conducted. Experimental data of pressure loss were collected for water-based mud and then compared with the calculated ones. The operational condition was at $50^{\circ} \mathrm{C}$, in a straight pipe line with $30-\mathrm{cm}$ length, 11.5 -mm diameter, made of CPVC, with a flow rate of $0.26 \mathrm{~m} 3 / \mathrm{h}$ (laminar regime). To calculate the pressure loss, the following was used,

$$
P_{d}=f\left(\frac{L}{D}\right)\left(\frac{\bar{v}^{2}}{2}\right)\left(\frac{\rho}{10^{2}}\right)
$$

where

$$
f=\frac{64}{R e_{P L}}
$$

and

$$
\operatorname{Re}_{P L}=\frac{D \bar{v} \rho}{K\left(\frac{8 \bar{v}}{D}\right)^{n-1}\left(\frac{3 n+1}{4 n}\right)^{n}} .
$$

with $P_{d}$ being the calculated pressure drop, $L$ the length of the pipe, $D$ the internal diameter, $\bar{v}$ the average velocity of the fluid, $\rho$ the specific mass of the fluid, and $K$ and $\mathrm{n}$ the power law parameters provided by the online and offline instruments. The results are shown in Table 8.

Table 8. Estimated pressure drop in a straight pipe line for a water-based drilling fluid, at 50oC, laminar regime.

\begin{tabular}{ccccc}
\hline Instrument & $K$ & $n$ & $\begin{array}{c}P_{d} \text { (mBar) } \\
\text { calculated }\end{array}$ & $\begin{array}{c}P_{d} \text { (mBar) } \\
\text { experimental }\end{array}$ \\
\hline TT-100 & 1.34 & 0.50 & 34.39 & $0.41 \%$ \\
FANN 35A & 3.15 & 0.39 & 41.67 & 34.25 \\
pipe & 2.60 & 0.40 & 36.54 & $6.27 \%$ \\
\hline
\end{tabular}

It can be seen that the viscometer that provided the smallest error (calculated value - experimental value) was TT-100, even with its deviance after $750 \mathrm{~s}-1$.The pipe viscometer provided a small error, and FANN 35A the highest one, although the steadiest curve. These results reinforce the notion that not always the best fit of rheological data generates the best prediction of pressure loss. In this case, the best prediction of pressure drop was given by the TT-100 rheological measurement. 


\section{CONCLUSIONS}

Within a fluid loop, this work developed and installed two online viscometers to measure drilling fluid rheological behavior simulating a well-drilling operation. One was a modified Couette viscometer and the other a standard pipe viscometer. For validation, the study compared the performance of both instruments with FANN 35A, which is an offline viscometer that the petroleum industry commonly uses as benchmark.

For a Newtonian fluid, agreement was found in all instruments between data for viscosity, proving that the devices were properly calibrated and installed. For nonNewtonian fluids, there were divergences in the powerlaw parameters provided by each instrument, both for drilling fluid (with suspended solids) and polymeric solution. Similar results were observed in the previously cited literature. These divergences were investigated and the probable main causes were found to be the following: effects of homogeneity, slipperiness, and interactions in the fluid/gap interfaces. In addition, a case study was carried out that demonstrated that these divergences were not significant if the parameters were used for pressure drop calculations. As an overall conclusion, the methodology proposed can be used to obtain online measurements of drilling fluid rheological behavior as well as online prediction of friction loss. In consequence, this paper contributes significantly to overcome the initial steps toward a fully automated drilling operation.

\section{ACKNOWLEDGEMENTS}

This work is developed by a partnership between PPGEQ/UFRRJ and CENPES/PETROBRÁS under the thematic network of research and engineering. The authors wish to acknowledge CENPES for their financial and service support.

\section{NOMENCLATURE}

$\begin{array}{lll}\text { Symbol } & \begin{array}{l}\text { Description } \\ \tau\end{array} & \text { Unit (SI) } \\ \mathrm{k} & \text { Elastic constant } & \mathrm{Pa} . \mathrm{s} \\ \mathrm{K} & \begin{array}{l}\text { Consistency index } \\ \mathrm{N} . \mathrm{m} / \mathrm{degree}\end{array} & (\mathrm{kg} / \mathrm{m})^{*}(1 / \mathrm{s})^{2-\mathrm{n}} \\ \mathrm{H} & \begin{array}{l}\text { Height of the inner } \\ \text { cylinder }\end{array} & \mathrm{m} \\ & \begin{array}{l}\text { Deflected angle } \\ \theta\end{array} & \text { Degree } \\ \dot{\gamma} & \text { Shear rate } & 1 / \mathrm{s} \\ \varnothing & \text { Correction Factor } & \text { Dimensionless } \\ r_{2} & \text { Outer cylinder radius } & \mathrm{m} \\ r_{1} & \text { Inner cylinder radius } & \mathrm{m} \\ \omega & \text { Angular velocity } & \mathrm{rad} / \mathrm{s} \\ \beta & \text { Radius ratio Dimensionless }\end{array}$

\begin{tabular}{|c|c|c|}
\hline $\mathrm{n}$ & Behavior index & Dimensionless \\
\hline n' & $\begin{array}{l}\text { Pseudo behavior } \\
\text { index }\end{array}$ & Dimensionless \\
\hline $\mathrm{P}$ & Pressure & $\mathrm{Pa}$ \\
\hline $\mathrm{z}$ & Orientation index & \\
\hline & Cartesian) & - \\
\hline $\mathrm{x}$ & $\begin{array}{l}\text { Orientation index } \\
\text { (Cartesian) }\end{array}$ & - \\
\hline $\mathrm{r}$ & $\begin{array}{l}\text { Tube or pipe position } \\
\text { on radius }\end{array}$ & $\mathrm{m}$ \\
\hline $\mathrm{L}$ & Tube or pipe length & $\mathrm{m}$ \\
\hline $\mathrm{v}$ & Velocity of the fluid & $\mathrm{m} / \mathrm{s}$ \\
\hline $\bar{v}$ & $\begin{array}{l}\text { Average velocity of } \\
\text { the fluid }\end{array}$ & $\mathrm{m} / \mathrm{s}$ \\
\hline $\mathrm{R}$ & Tube or pipe radius & $\mathrm{m}$ \\
\hline hd & $\begin{array}{l}\text { Friction loss in a straight } \\
\text { pipe line }\end{array}$ & $\mathrm{m}$ \\
\hline Q & Volumetric flow rate & $\mathrm{m}^{3} / \mathrm{s}$ \\
\hline$f$ & Friction factor & Dimensionless \\
\hline $\mathrm{H}$ & $\begin{array}{l}\text { Height of the inner } \\
\text { cylinder }\end{array}$ & $\mathrm{m}$ \\
\hline $\mathrm{D}$ & Tube or pipe diameter & $\mathrm{m}$ \\
\hline g & Gravity & $\mathrm{m} / \mathrm{s}^{2}$ \\
\hline RePL & $\begin{array}{l}\text { Reynolds for Power } \\
\text { Law fluids }\end{array}$ & Dimensionless \\
\hline wi & $\begin{array}{l}\mathrm{i}^{\text {th }} \text { element of the array } \\
\text { or matrix weight }\end{array}$ & Dimensionless \\
\hline$\hat{y}_{i}$ & $\begin{array}{l}\mathrm{i}^{\text {th }} \text { element of the array } \\
\text { or matrix of best fit }\end{array}$ & According to data \\
\hline yi & $\begin{array}{l}\mathrm{i}^{\text {th }} \text { element of the array } \\
\text { or matrix of observed } \\
\text { values }\end{array}$ & According to data \\
\hline $\mathrm{N}$ & $\begin{array}{l}\text { Size of the array } \\
\text { or matrix }\end{array}$ & Dimensionless \\
\hline
\end{tabular}

\section{REFERENCES}

Apaleke, A. S, Al-Majed, A. and Hossain, M. E., Drilling fluid: state of the art and future trend. North Africa technical conference and exhibition, Cairo, Egypt. SPE 149555 (2012).

Barnes, H. A., A Handbook of Elementary Rheology, Institute of Non-Newtonian Fluid Mechanics, University of Wales (2000).

Billon, H.H., Shear Rate Determination in a Concentric Cylinder Viscometer, DSTO Aeronautical and Maritime Research Laboratory, PO Box 4331, Melbourne Victoria 3001. Publication track AR-009-701, DSTO-GD-0093 (1996).

Bird, R.B, Steward, W.E. and Lightfoot, E.N., Transport Phenomena. Second Edition. Chemical Engineering Department. University of Wisconsin-Madison (2001).

Brookfield viscometers, Instruction Manuals and Guides (1993).

Broussard, S., Gonzalez, P., Murphy, R. and Marvel, C., Making Real-Time Fluid Decision with Real-Time Fluid Data at the Rig Site. Society of Petroleum Engineering (SPE).SPE 
Drilling Conference and Exhibition, Abu Dhabi, UAE.SPE 137999 (2010).

Caenn, R. and Chillingar, G.V., Drilling fluids: State of the Art. Journal of Petroleum Science and Engineering. 14, 221-230 (1996).

Craft, Holden and Graves, Well Design: Drilling and Production. Prentice - Hall, Inc. Englewood Cliffs, New Jersey (1962).

Carlsen, L. A. and Nygaard, G., Utilizing Instrumented Stand Pipe for Monitoring Drilling Fluid Dynamics for Improving Automated Drilling Operations. Proceedings of the 2012 IFAC Workshop on Automatic Control in Offshore Oil and Gas Production, Norwegian University of Science and Technology, Trondheim, Norway (2012).

FANN instruments, revision J 208878. Model 35 Viscometer Instruction Manual.

Gandelman, R. A., Martins, A. L., Teixeira, G. T., Aragão, A. F. L., Neto, R. M. C., Lins, D. G. M., Lenz, C., Guilardi, P. and Mari, A., Real Time Drilling Data Diagnosis Implemented In Deepwater Wells - A Reality, OTC-24275-MSOTC-24275MS, Rio de Janeiro, October 29th to 31th, Brazil (2013).

Himmelblau, D.M. and Riggs, J. B., Basic Principles and Calculations in Chemical Engineering: International Edition, 7/E. Pearson Education. University of Texas, Austin (2013).

LabView ${ }^{\circledR}$ instruction manual and online Help(2011).

Macosko, C. W., Rheology: Principles, Measurement and Applications. Wiley-VCH - Inc. Originally publish as ISBN 1-56081-579-5 (1994).
Meyer, S. L., Data Analysis for Scientists and Engineers, Wiley ISBN 0-471-59995-6 (1975).

Morrison, F. A., Understanding Rheology, Oxford University Press, Inc. ISBN 0-19-514166-0 (2001).

Oort, E. V. and Brady, K., Case-Based Reasoning System Predicts Twist-off in Louisiana Well Based on Mideast Analog. Special Focus - Drilling Technology (2011).

Paraíso, E. C. H., Study of cement slurries flow in circular and concentric annular ducts, Thesis, Federal Rural University of Rio de Janeiro (2011).

Rondon, J., Barrufet, M. A. and Falcone, G., A novel downhole sensor to determine fluid viscosity. Flow Measurement and Instrumentation, 23, 9-18(2012).

Saasen, A., Omland, T. H., Ekrene, S., Breviere, J., Villard, E., Kaageson-Loe, N., Tehrani, A., Cameron, J., Freeman, M., Growcock, F., Patrick, A., Stock, T., Swaco, M.I., Jørgensen, T., Reinholt, F., Scholz, N., Amundsen, H. E. F., Steel,e A., and Meeten, G.,Automatic Measurement of Drilling Fluid and Drill Cuttings Properties. IADC/SPE Drilling Conference (2009).SPE Drilling \&Completion, 24(04), 611-625 (2009).

Shaughnessy, J., Daugherty, W., Graff, R. and Durkee, T., More Ultra-Deepwater Drilling Problems. SPE/IADC Drilling Conference, ID: 105792-MS. ISBN 978-1-55563-158-1 (2007).

Vajargah., K. andvan Oort., E., Determination of drilling fluid rheology under downhole conditions by using real-time distributed pressure data. Journal of Natural Gas Science and Engineering, 24, 400 - 411 (2015). 